\title{
Design, fabrication and testing of a prototype, thin-vaulted, unreinforced concrete floor
}

\author{
A. Liew*, D. López López, T. Van Mele, P. Block \\ ETH Zurich, Switzerland
}

\section{A R T I C L E I N F O}

\section{Article history:}

Received 1 July 2016

Revised 24 January 2017

Accepted 31 January 2017

\section{Keywords:}

Prototype

Thin

Vault

Unreinforced

Concrete

Arch

Funicular

Compression

Ribbed

Floor

\begin{abstract}
A B S T R A C T
This paper describes the concept, form finding, fabrication and experimental testing of a prototype floor system, derived from principles of shallow arching action, to initiate internal compressive stresses rather than exclusively flexural stresses. This vaulting in a floor system leads to a lightweight structural element, with significant weight savings compared to traditional concrete floor slabs. The form finding process to generate the floor geometry is presented, with a description of the fabrication process, the concrete mix design, material testing and experimental testing. The results from the serviceability and ultimate load testing of the prototype floor are documented in detail. The data showed that the floor unit was both stiff under service load, with maximum vertical deflections less than span/2500, as well as possessing sufficient strength for ultimate loading, carrying 2.5 times the factored design load in a more critical asymmetric loading scenario. A camera setup was used to measure displacements in-line with traditional displacement transducers, to give contour plots of vertical deflections.
\end{abstract}

(c) 2017 Elsevier Ltd. All rights reserved.

\section{Introduction}

This research describes a prototype of a pre-fabricated modular floor, which will be utilised at the NEST-HiLo research and innovation unit [1] for the Swiss Federal Laboratories for Materials Science and Technology (Empa), Dübendorf, Switzerland (Fig. 1). The NEST-HiLo unit is a collaboration between the Institute of Technology in Architecture, represented by the Professorships of Architecture and Structure (Block Research Group) and Architecture and Building Systems, architectural office Supermanoeuvre, and engineering firm Bollinger + Grohmann. HiLo (High performance, Low energy) demonstrates innovations in the domains of lightweight construction as well as smart, integrated and adaptive building systems. HiLo is planned as a duplex penthouse apartment for visiting faculty. Four innovations are introduced: (1) an integrated, thin-shell roof [2], constructed with a lightweight, flexible formwork system, (2) an adaptive solar facade [3], (3) an automated, occupant-centred control system, and (4) the integrated, lightweight, funicular floor system as presented in this paper. Four floor units of unique geometry, with average dimensions of $5 \mathrm{~m}$ by $5 \mathrm{~m}$ (Fig. 2), will be placed above the main bedrooms and bath-

\footnotetext{
* Corresponding author.

E-mail address: liew@arch.ethz.ch (A. Liew).
}

rooms. The construction works are due to be completed in 2018 . The vaulted floor system will be a thermally active building element. The system contains an integrated hydronic pipe network within the depth, which provides heating and cooling to the bedrooms through the thin $(20 \mathrm{~mm})$ concrete radiant panel at ceiling level [4]. The internal voids in-between ribs can be used for services integration.

The floor system's structural principle, as shown in the geometry of the reduced-scale prototype in Fig. 3, is based on shallow arching action to initiate internal compressive stresses rather than exclusively flexural normal stresses, leading to a lightweight and stiff structure.

The concept stems from thin-tile compression vaults stiffened by diaphragms or ribs, a technique that has a long tradition in the Mediterranean and in the United States in the nineteenth century when Rafael Guastavino exported the technique and developed many patents [5] (Fig. 5). The ribs allow a floor to be supported at the topside by transmitting the loads to the vault, as well as stiffening the structure, the latter of which is important for resisting asymmetric loading. In order to carry the loads efficiently in compression, ties or horizontal restraints are needed to absorb the thrust (Fig. 4). Investigations by the Block Research Group into this concept can be found in the SUDU (Sustainable Urban Dwelling Unit) prototype in Addis Ababa, Ethiopia (Fig. 6), 


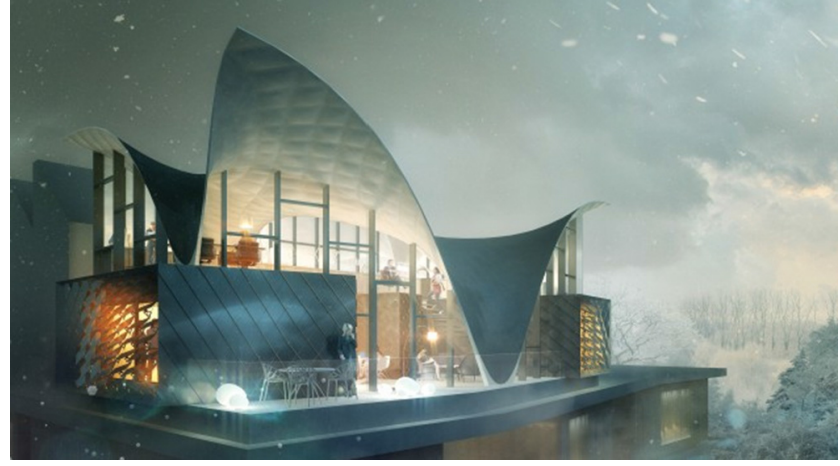

Fig. 1. The NEST-HiLo research and innovation unit at Empa, Dübendorf, Switzerland (image: Supermanoeuvre/Doug \& Wolf).

which is an example of a thin, unreinforced masonry vault with ribs, supported by lightly reinforced edge beams connected by ties [6,7]. In this case, the African floor system limits the amount of material required by featuring a funicular geometry for the vault and adding structural depth using the two different strategies showed in Guastavino's patent: the construction of lightweight stiffening walls and the addition of stabilised fill. This allows the system to resist asymmetric live loading and permits thin stiffening elements that are stabilised by the compacted fill. Note that in a building with a main skeleton frame structure, the floor system could be integrated without explicit ties, relying on the frame to absorb the horizontal thrusts.

For the prototype floor presented in this paper, the ties are replaced by stiff corner elements mounted onto a stiff steel testing frame. The structure is constructed from fibre-reinforced, ultrahigh strength, self-compacting concrete, with a global thickness of $20 \mathrm{~mm}$. The form finding process constructs a funicular network through constrained Thrust Network Analysis [9,10], with an algorithm that generates the floor geometry. The design process includes three steps, corresponding to the typical types of structural optimisation: topology, shape and size optimisation [11]. The floor was experimentally tested to confirm the design assumptions via serviceability and ultimate load testing. This was to investigate the structural performance of the floor, and use the data and experience to quantitatively and qualitatively inform the actual floor units that will be constructed on the NEST building.

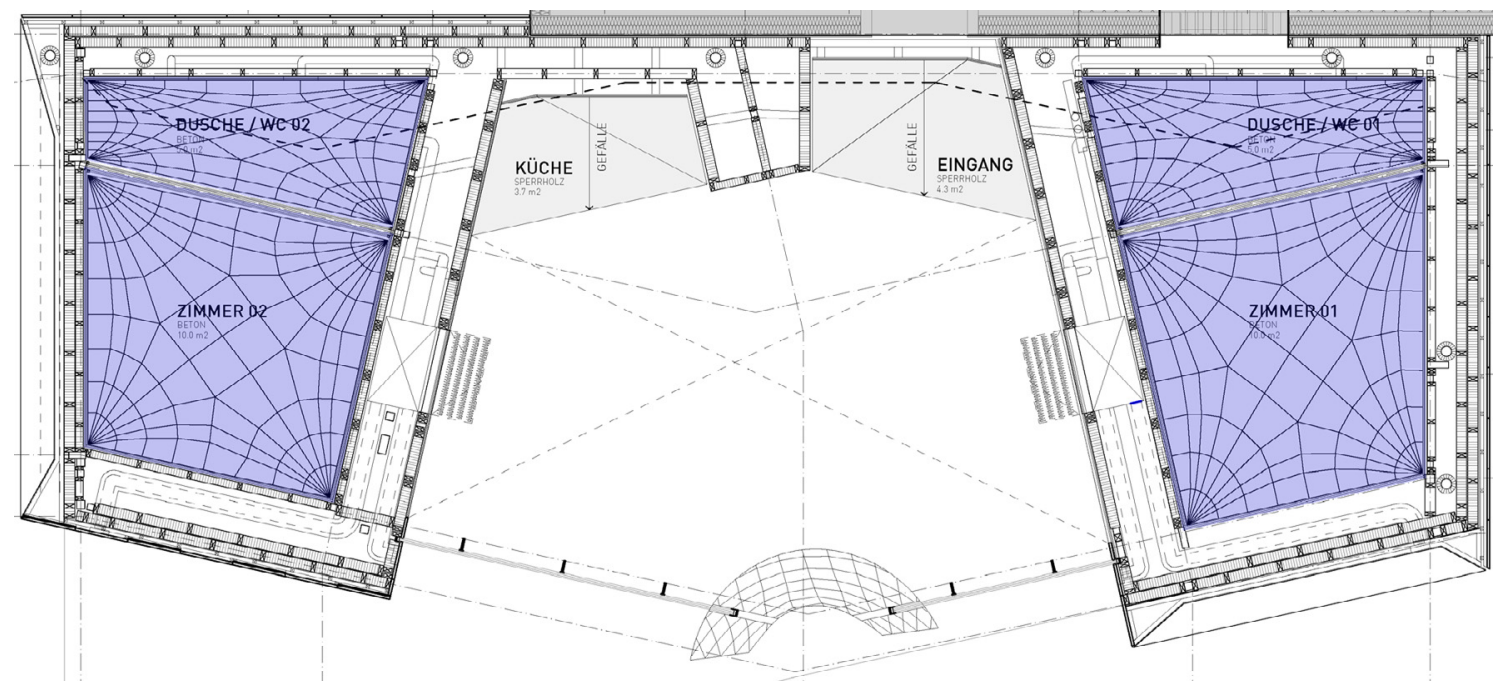

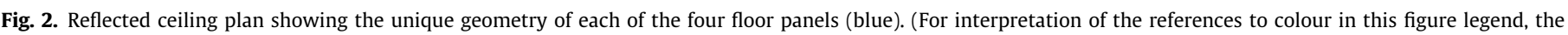
reader is referred to the web version of this article.)

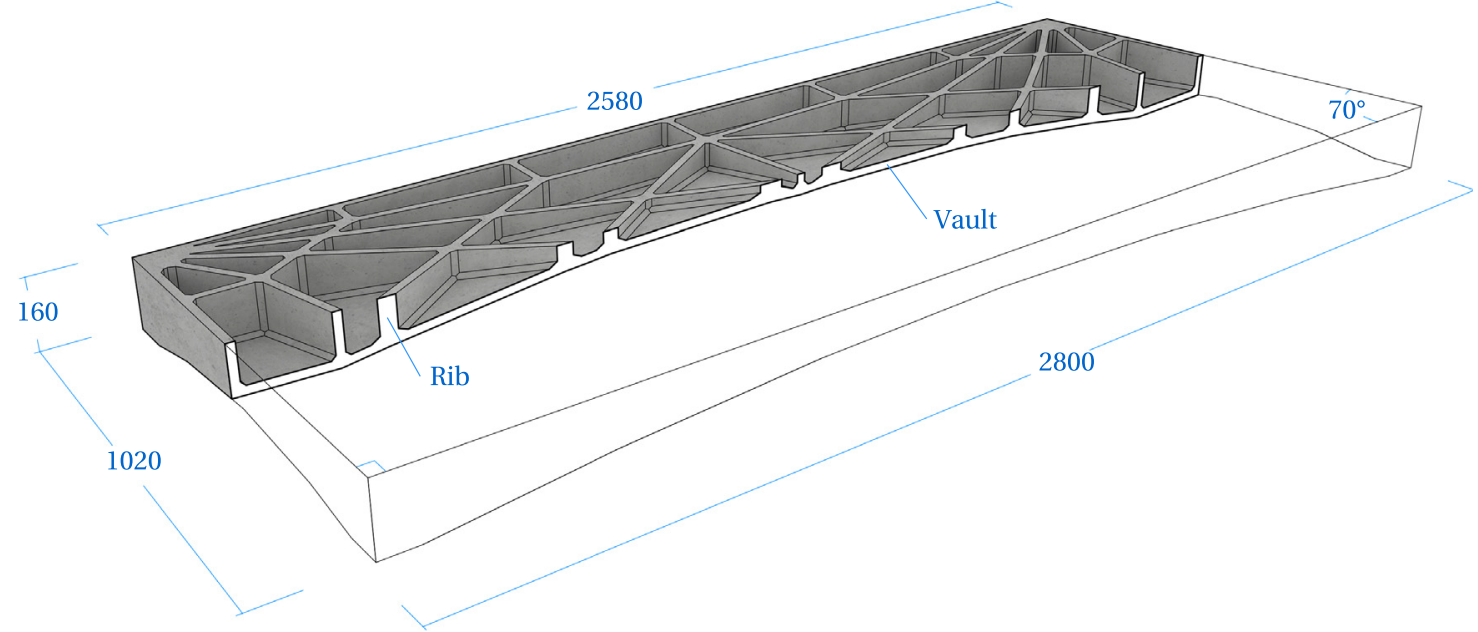

Fig. 3. Longitudinal section through the floor, which rests on its four corners. Key dimensions in mm. 


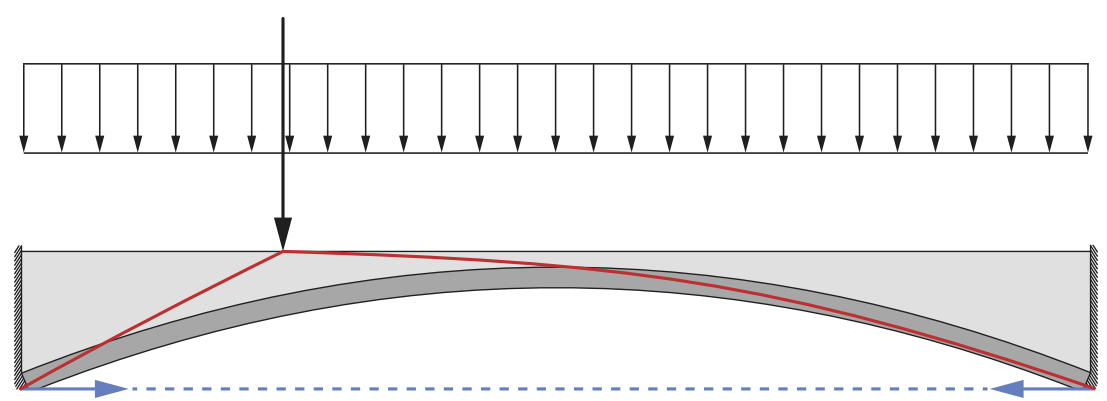

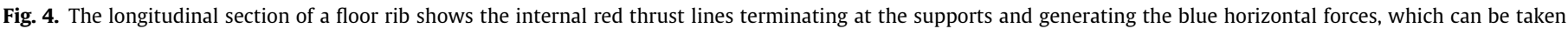
either by ties or horizontal restraints.

\section{Guastavino Rib And Dome System}

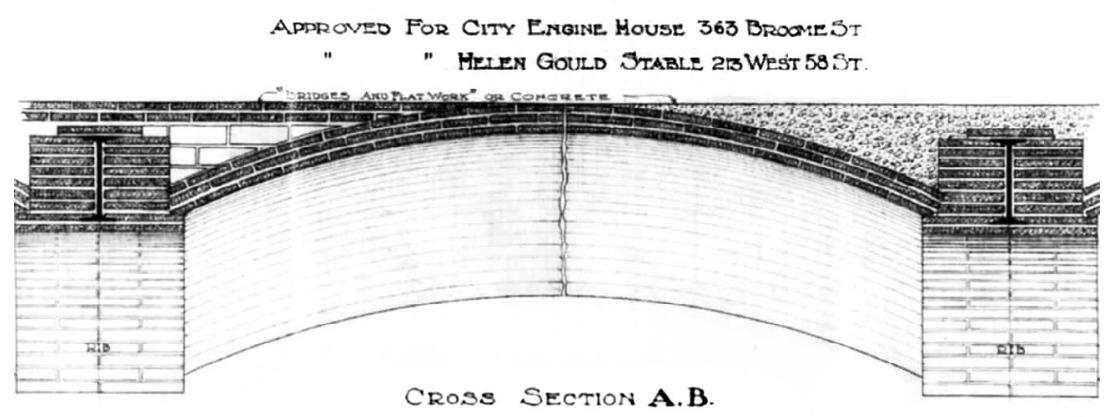

SCALE 1"ONe. Foot

Fig. 5. Guastavino rib and dome system, New York, 1902 [8].

This research paper is laid out as follows: Section 2 describes the geometry of the floor, including an outline of the form finding process to generate this form, and a description of the subsequent digital fabrication process. Section 3 details the self-compacting, ultra-high strength concrete mix and the results from the compressive and tensile material tests. The experimental setup used in the serviceability and ultimate loading tests is described in Section 4, where the fixed supports, loading system and displacement measuring instruments are detailed. The load-displacement and load-time histories from the cyclic serviceability loading regime and asymmetric ultimate loading scheme can be found in Section 5 , with conclusions finalised in Section 6.

\section{Form and fabrication}

This section gives the stages of the form finding process in Section 2.1, a description of the floor geometry in Section 2.2, and an outline of the digital fabrication process in Section 2.3.

\subsection{Form finding}

The form finding procedure utilises RhinoVAULT [12,13], which allows the creation of compression-only surface structures. Using new extensions of the software, it was possible to account for the nonuniform self-weight of the floor and include the additional dead-load of floor finishes. From Fig. 7, the first step is to draw in plan the network of lines forming the rib pattern. This starting pattern derives from ribbed masonry vaults and is influenced by the expected flow of forces to the supports. The rib pattern is form found into a compression-only solution with RhinoVAULT, such

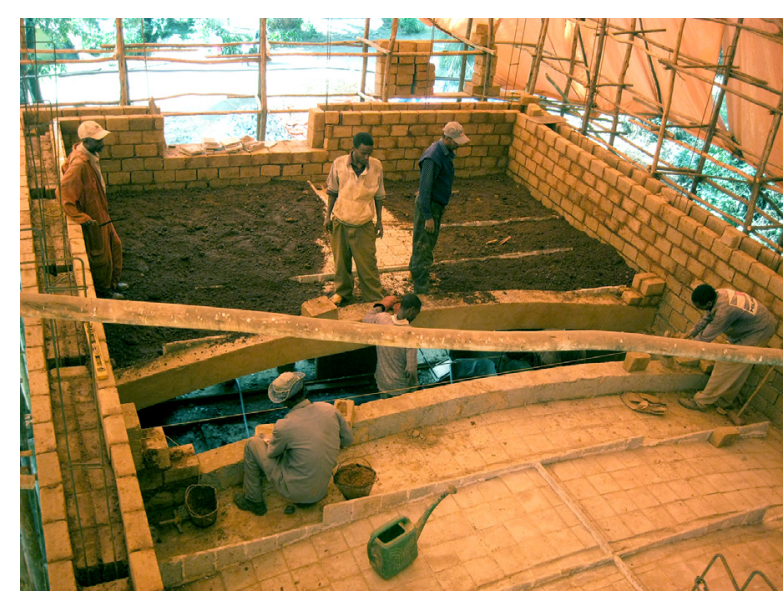

Fig. 6. Unreinforced, rib-stiffened thin floor vaults of the SUDU project in Addis Ababa, Ethiopia, 2010.

that the planar network of lines is now optimised both in plane and out of plane forming the depth of the floor structure. As the sides of the rib pattern contract inwards as a consequence of the form finding, forming edge arches spanning between the supports, lunettes are added to the gaps on each side of the floor to preserve the quadrilateral shape. Such a solution has historically been used to fit domed or vaulted surfaces in polygonal or quadrilateral shapes in plan.

An initial geometry is thus created at the end of this first step and the shape can be optimised to account for the design loading. The applied design loading for the floor area was taken into 


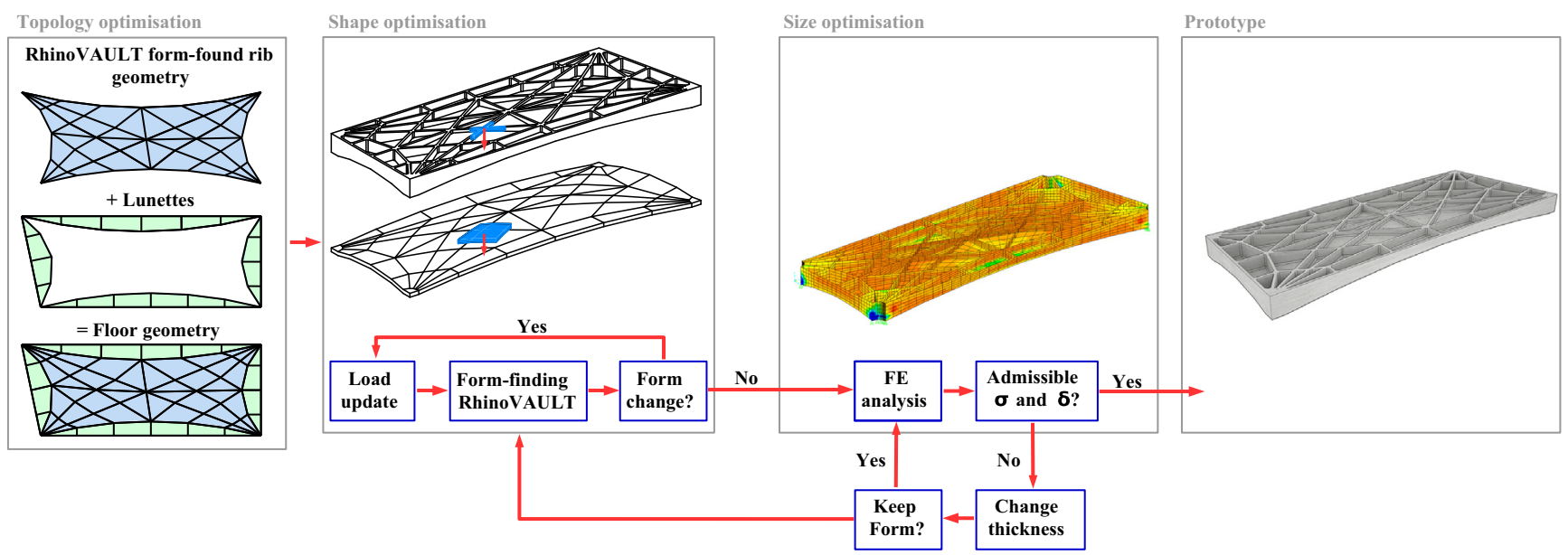

Fig. 7. Flow-chart of the form finding process to generate the floor geometry.

account according to the Swiss building codes [14], and is based on a superimposed dead-load upon the deck of $1.0 \mathrm{kN} / \mathrm{m}^{2}$, a live-load of $2.0 \mathrm{kN} / \mathrm{m}^{2}$, and the self-weight contributing an additional $3.95 \mathrm{kN}$ from the floor mass of $403 \mathrm{~kg}$. Combinations of additional $2.0 \mathrm{kN}$ point loads were applied at various rib intersections to check for the occurrence of tensile stresses or excessive deformations. A $2.0 \mathrm{kN} / \mathrm{m}^{2}$ live-load on half of the floor was also checked as part of an asymmetric loading combination. The load combinations used safety factors of $G_{\mathrm{k}}=1.35$ for dead-loads and $Q_{\mathrm{k}}=1.50$ for live-loads. Area loads were applied through tributary areas around each node, such that equivalent point loads act at each of the rib intersection. The weight of the ribs was calculated from the local depth, thickness and density of concrete. Iterative form finding was performed using these new loads for each node until convergence to a final geometry.

Once the shape optimisation was complete, a structural analysis was performed via the finite element analysis software SAP2000 [15]. This structural analysis step determined whether the resulting stresses $\sigma$ and deformations $\delta$, for all of the intended load cases, were admissible given the design code and material strength limits. This then allowed the designation of the rib and vault thickness based on the internal stresses, with a drive for minimum thickness for the lowest possible weight. From this step, it was determined that a constant rib and vault thickness of $20 \mathrm{~mm}$ was sufficient for admissible stresses (compressive and tensile) as well as for stiffness in deflection control using a limit of span/500. Given that the floor is designed as unreinforced, the steel fibre strength was not included in the structural analysis, and so it was a conservative assumption to use only the tensile capacity of the concrete to govern the design. The concrete's tensile capacity for the structural analysis was estimated conservatively as $1.5 \mathrm{~N} / \mathrm{mm}^{2}$; later, material tests would show a much higher strength (see Section 3.2).

A local volume of concrete thicker than $20 \mathrm{~mm}$ is present at each corner, to alleviate any potential stress concentrations from the forces converging at the supports. Different material properties, thickness, boundary conditions and load combinations were investigated parametrically, along with various possible construction process conditions and loading cases. These separate loading cases related to lifting of the floor in various lifting configurations, and for the positioning of the floor into the test rig. These were all considered separately and were not governing to the design. Once all design checks had been satisfied, the prototype geometry was complete.

The performance of the elements composing the floor system: the funicular vault and the stiffening ribs, as independent elements, and the efficiency of the combination of both combined, were also tested with the finite element models. Figs. 8 and 9 show the vault-only, ribs-only and the combined models for two loading combinations: (1) dead-load + distributed live-load (2) dead-load $+2.0 \mathrm{kN}$ point load at one side of the floor. Both models respond well to distributed loads, with the vault-only and the ribs-only models exceeding the assumed tensile strength with maximum tensile stresses of $2.9 \mathrm{~N} / \mathrm{mm}^{2}$ and $3.3 \mathrm{~N} / \mathrm{mm}^{2}$, respectively. In any load combination including point loads, tensile stresses increased dramatically for these component models. The combined vault and ribs models satisfied comfortably all load combinations, with maximum tensile stresses of $0.8 \mathrm{~N} / \mathrm{mm}^{2}$ and $1.5 \mathrm{~N} / \mathrm{mm}^{2}$ for the distributed and point load cases.

\subsection{Geometry}

The floor geometry that results from Section 2.1 , is of a trapezium shape in plan, is stiffened with internal vertical ribs, possesses a flush top surface, and has void spaces above a thin vault base. A longitudinal section through the floor was shown in Fig. 3, displaying the width of $1020 \mathrm{~mm}$, maximum height of $160 \mathrm{~mm}$ and side lengths between 2580 and $2800 \mathrm{~mm}$, giving the structure a relatively high span-to-depth ratio of 34 . The average density of the concrete was $2427 \mathrm{~kg} / \mathrm{m}^{3}$, which coupled with the volume and plan area of the floor, lead to an average mass of $119 \mathrm{~kg} / \mathrm{m}^{2}$. The floor was designed to be fixed from translating laterally at its supports and designed to mobilise arching action through the ribs and underlying vault, both of which were $20 \mathrm{~mm}$ thick. The ribs varied between $20 \mathrm{~mm}$ and $140 \mathrm{~mm}$ in height, and as a consequence, the mid-span ribs were shorter than at the corners. This rib pattern is effective at reducing effective lengths for local buckling, as unsupported lengths are kept short and the rib-height is minimised.

As the floor element promotes shallow arching/vaulting action in preference to flexural action, the supports at the corners must restrain the horizontal thrusts. These can be efficiently taken via four (pre-stressed/post-tensioned) tie elements around the perimeter of the floor, as will be the case in the real NEST HiLo floor. If the stiffness of the restraining horizontal forces is sufficient, the arching action can develop internal compressive stresses. However, if the horizontal restraint is flexible or absent, the element will behave as a simply supported slab element and attract the associated tensile stresses from bending.

Loading of the floor takes place either through direct vertical loading of the nodes (the rib intersections), or distributed over the top surface of the ribs via a diaphragm. The floor's structural behaviour is then predominantly via arching action following the 


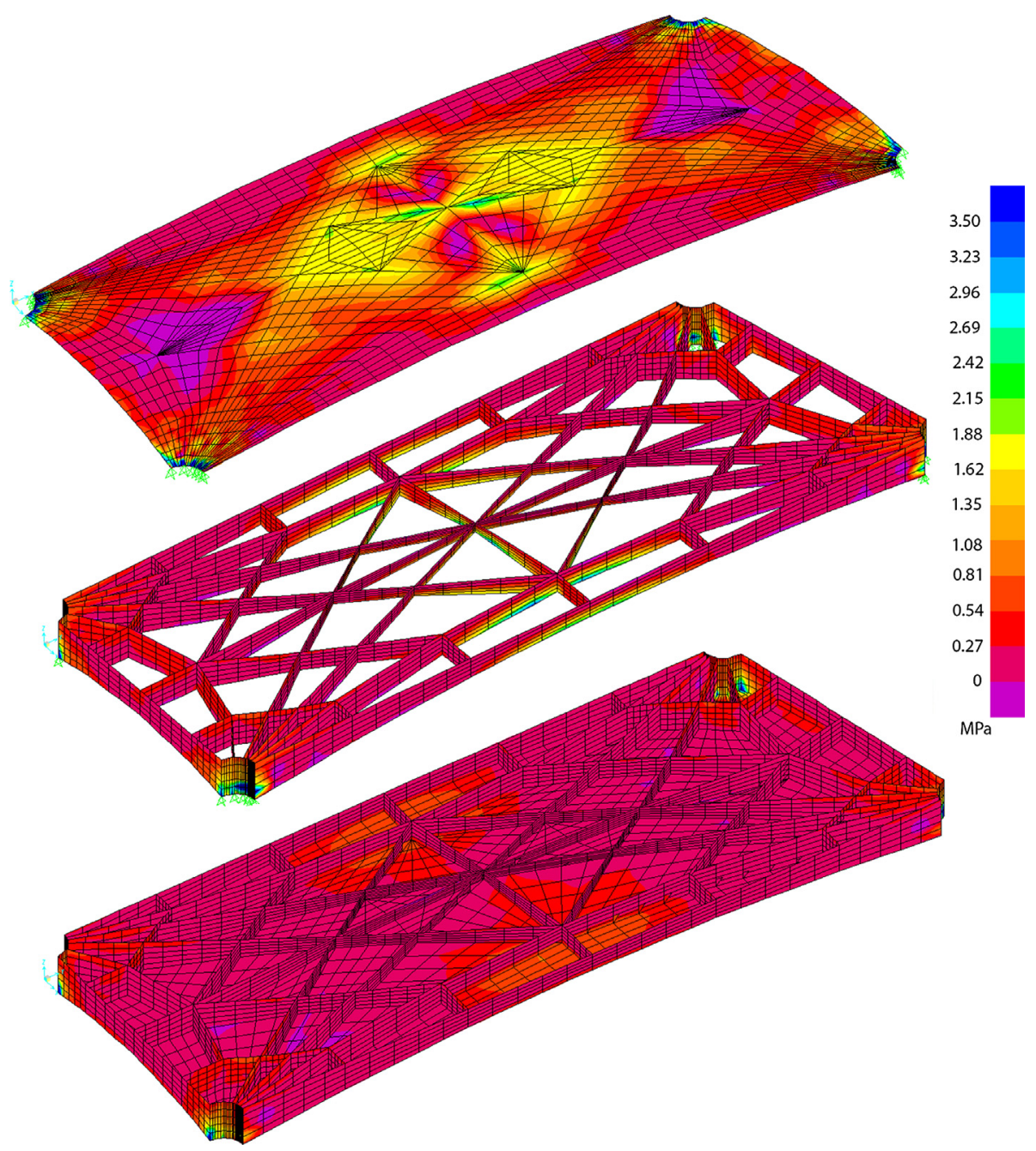

Fig. 8. Comparison of stresses [MPa] for the FE models: vault-only (upper), ribs-only (middle) and combined (lower), subject to distributed loading.

vault diagonals and ribs, terminating at the corner supports, where the horizontal thrusts are taken by the supports or ties.

\subsection{Fabrication}

CNC (Computer Numerical Control) milling and wire-cutting techniques involving a custom wire-cutter and control software [16] were used to produce the double-sided mould from EPS (Expanded Polystyrene) foam and timber. Fig. 10 shows an exploded view of the fabrication with the layers as follows: (a) the CNC-milled wooden cover frame, (b) arrangement of wire-cut foam blocks for the floor voids and rib formations, (c) the concrete element itself, (d) base layer of CNC-milled foam blocks forming the double-curved vault, and (e) the supporting wooden casing. The actual poured element can be seen in Fig. 11. The lower side of the mould consisted of a wooden case in which CNC milled foam blocks shaping the funicular vault were inserted. Wire-cut foam blocks were glued onto a wooden $\mathrm{CNC}$ milled frame to make up the upper side of the mould, which would shape the stiffening ribs. This frame would be supported on its perimeter on the top edges of the lower mould.

The lower surface of the wire-cut foam blocks remained at a distance of $20 \mathrm{~mm}$ from the lower funicular formwork. A latexbased coating was applied to the mould to assist in the striking of the formwork when removing the foam, and for ensuring a quality surface finish. Furthermore, smooth edges and corners were designed for the foam blocks to ease their removal after the curing of the concrete. The recipe of the high-performance, selfcompacting, fibre-reinforced concrete had to be carefully selected to posses the flowability required to pour the concrete into the $20 \mathrm{~mm}$ thick spaces for the ribs and vault.

\section{Material properties}

Material tests were performed on the ultra-high-strength, fibrereinforced concrete in the testing facilities at the Institute for Building Materials (IfB) at ETH Zurich. The concrete mix was based on the fibre-reinforced, self-compacting concrete mix (mix two) detailed in [17], where it was originally applied to $15 \mathrm{~mm}$ thick concrete plates, similar to the rib thickness of $20 \mathrm{~mm}$ used in this study. Having a self-compacting concrete was important given the difficulty in compacting the thin ribs. The design and analysis of the floor system assumed that the concrete was unreinforced, however steel fibres were included to (1) improve the structure's performance during transport and handling, (2) deal with stress concentrations, (3) improve the ductility, and (4) to control crack growth. A summary of the concrete mix is presented as follows, with more detailed information found in [18]:

- $1.0 \mathrm{~kg}$ of cement (Holcim Normo 5R, CEM I 52.5).

- $0.07 \mathrm{~kg}$ of microsilica (Elkem grade 971-U).

- $1.23 \mathrm{~kg}$ of aggregate $\leqslant 4 \mathrm{~mm}$. 


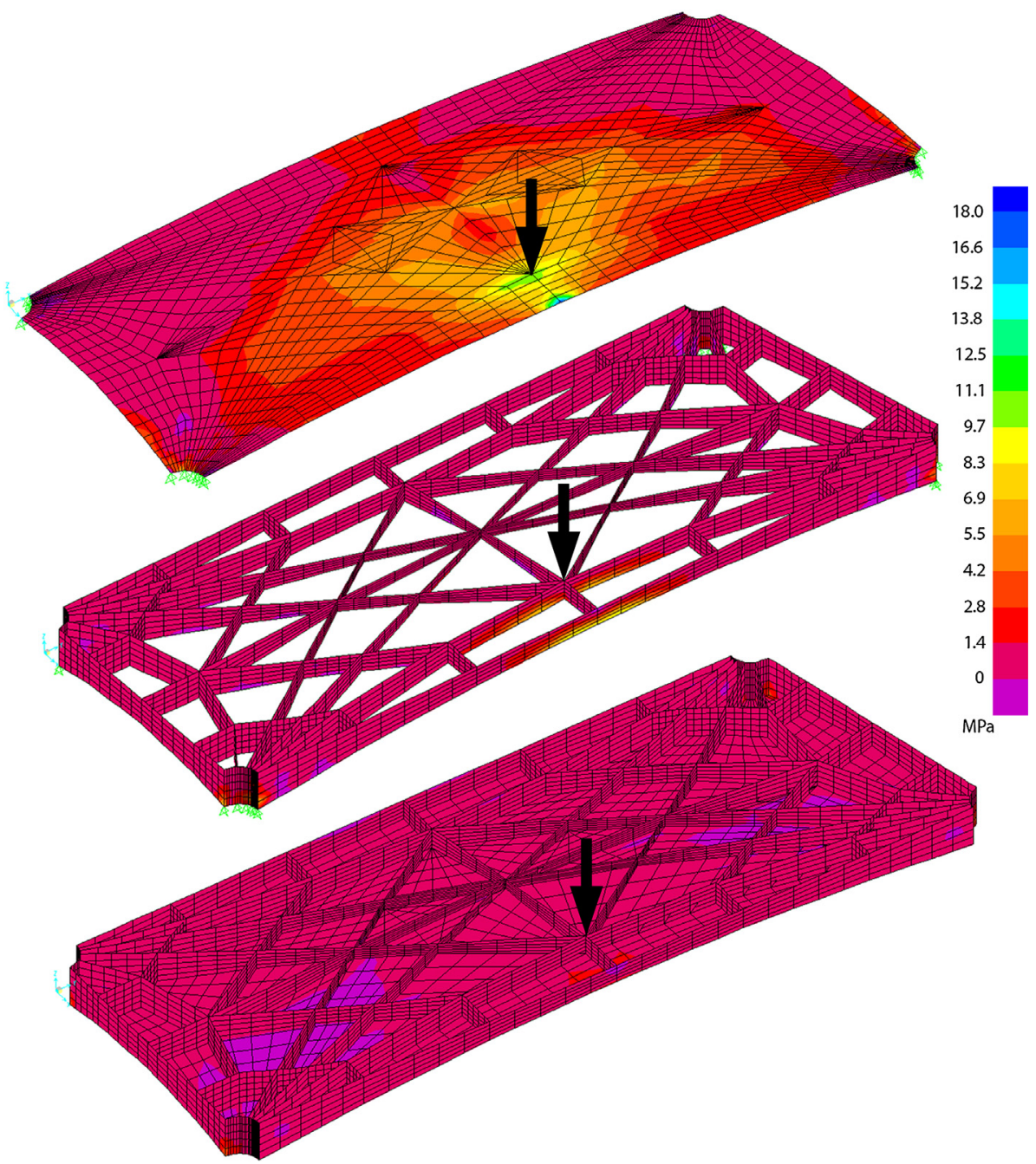

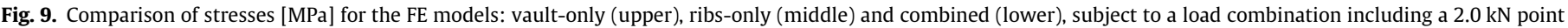
load.

- $0.25 \mathrm{~kg}$ of water.

- $0.023 \mathrm{~kg}$ of plasticiser (BASF Glenium ACE 30).

- $0.085 \mathrm{~kg}$ steel fibres (microfibres $12 \mathrm{~mm}$ ).

- The average density of the concrete was $2427 \mathrm{~kg} / \mathrm{m}^{3}$.

- The cast required $319 \mathrm{~kg}\left(0.13 \mathrm{~m}^{3}\right.$ of concrete).

In this research project, the material tests were performed on stub-column cylinders to determine the compressive strength in Section 3.1, and bending tests on rectangular beams to determine the tensile strength in Section 3.2.

\subsection{Compressive strength tests}

Eight concrete cylinders of nominal diameter $150 \mathrm{~mm}$ and height $300 \mathrm{~mm}$ were tested until their peak loads to determine the ultimate compressive strength of the concrete. All of the concrete cylinders were milled flat before placement and tested in a Walter + Bai test-rig. The specimens were labelled with the identifiers (ID) C1-C8 as shown in Table 1, and with the letter $\mathrm{F}$ or $\mathrm{N}$ appended to the end for when steel fibres were included in the mix or not. Failure was observed to be brittle, but not explosive, for specimens $\mathrm{C} 1-\mathrm{C} 6$, due to the presence of the steel fibres, however, specimens C7 and C8 failed energetically, breaking into many parts contained behind a protective plastic shield placed on the testing machine. Table 1 summarises the test results, and shows that the compressive strength $f_{c}\left[\mathrm{~N} / \mathrm{mm}^{2}\right]$ varied from 122.0 $146.1 \mathrm{~N} / \mathrm{mm}^{2}$ with a mean value of $139.3 \mathrm{~N} / \mathrm{mm}^{2}$, which is similar to the value of $144.7 \mathrm{~N} / \mathrm{mm}^{2}$ (56 days) reported in [17].

\subsection{Tensile strength tests}

Eight rectangular concrete beams with identifiers B1-B8, were tested in a three-point bending configuration to determine the tensile strength of the concrete by back-calculation from the crosssection stress-strain profile. The identifiers again have an $\mathrm{F}$ or $\mathrm{N}$ appended at the end for when steel fibres were included in the mix or not. The nominal cross-section dimensions for the heights and widths were $160 \mathrm{~mm} \times 150 \mathrm{~mm}$ respectively, with total lengths of $600 \mathrm{~mm}$ and spans of $500 \mathrm{~mm}$ between the steel roller supports.

Failure occurred via cracking at the extreme tensile fibres of the concrete cross-sections, with some resistance to tension provided by the steel fibres. The results of the tensile tests are summarised in Table 2, and show that the tensile strength $f_{\mathrm{t}}\left[\mathrm{N} / \mathrm{mm}^{2}\right]$ varied from 5.1 to $14.3 \mathrm{~N} / \mathrm{mm}^{2}$, with a mean value of $11.5 \mathrm{~N} / \mathrm{mm}^{2}$ for the fibre-reinforced mix, and less than half this value for the unreinforced mix, where the mean was $5.3 \mathrm{~N} / \mathrm{mm}^{2}$. The fibre-reinforced 
a)
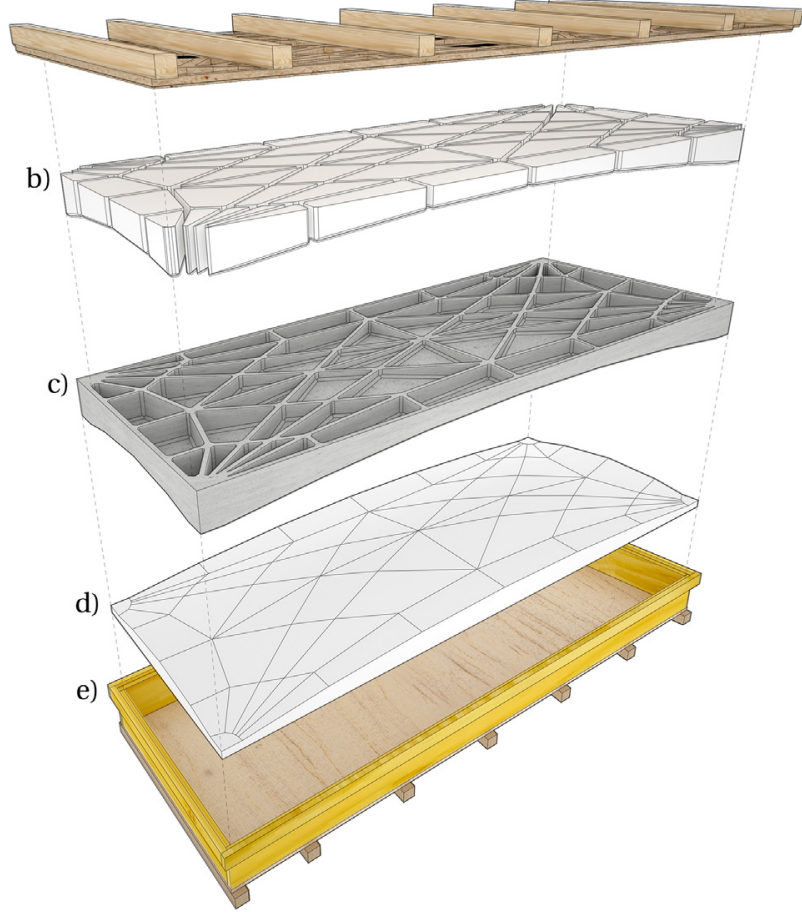

Fig. 10. Exploded view of the fabrication of the prototype floor.

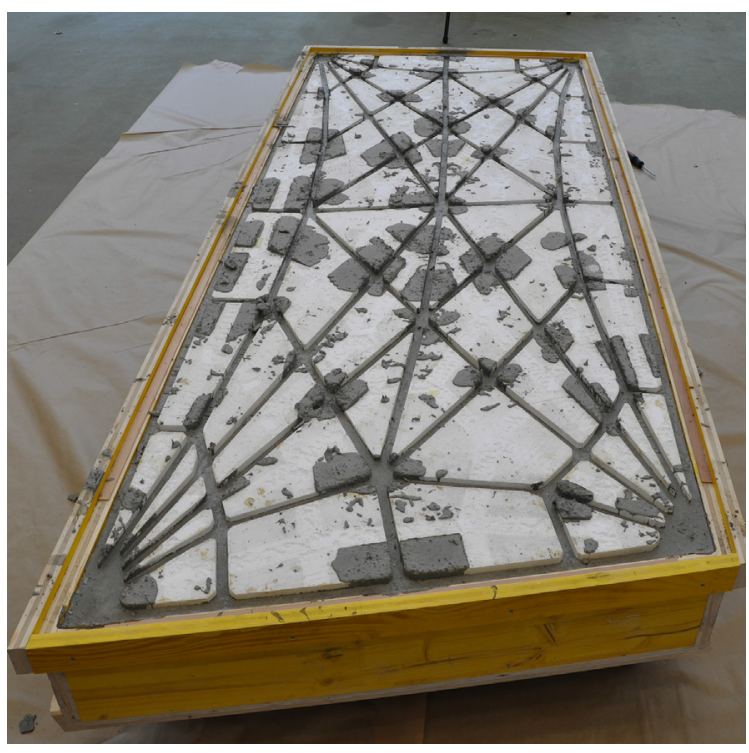

Fig. 11. Concrete poured into formwork, around wire-cut foam inserts. Image shows layers (b)-(e) from Fig. 10. tensile strength is slightly lower but comparable to the value of $14.2 \mathrm{~N} / \mathrm{mm}^{2}$ in [17].

\section{Experimental setup}

This section describes different components of the experimental setup: Section 4.1 provides information on the steel supports used at the four corners; Section 4.2 details the hydraulic loading system, test frame and spreader beams; Section 4.3 gives an overview of the GOM camera setup, which was used to generate the displacement point cloud; and finally, the displacement transducer array that measured vertical deflections, is explained in Section 4.4. The testing facilities were those at the HIF Bauhalle at the Institute of Structural Engineering (IBK) at ETH Zurich.

\subsection{Supports}

The corner support conditions, as seen in Fig. 12, consisted of custom-made angles constructed from, and stiffened with, $20 \mathrm{~mm}$ thick steel plate. The angles were each bolted with three M20 bolts into a stiff steel testing frame on top of intermediate elements to allow easy access underneath. These fixed supports were required to activate the horizontal boundary thrusts needed to initialise the arching action within the structure, as roller supports would only allow bending action. The steel angle supports were fabricated such that there was a sufficiently wide gap to cast grout in-between the steel plates and the floor corners, to ensure full surface contact. The floor was painted white over the entire surface for the clearer visualisation of any crack formations when testing the floor to failure.

\subsection{Loading}

For the application of the vertical load, hydraulic jacks were suspended from the testing frame's cross-beam and loaded webstiffened I-section spreader beams, which in turn loaded solid rectangular steel sections, to form a distributed line load across the full width of the floor. The webs of the spreader beams were carefully aligned to be central to the solid rectangular elements. The jacks were connected to an oil-hydraulic system, where the pressure was controlled by a manual lever-jack, with forces measured through attached pressure meters. For the serviceability loading, both loading lines were used, to give a four-point bending configuration (Fig. 13), while for the ultimate loading setup, only the right jack was used (Fig. 14), giving an asymmetric loading case. The weights of the intermediate steel members were weighed before testing and the total loads adjusted accordingly. The loading points were at approximately the quarter points along the main floor span, with the locations chosen to coincide with, or close to, as many rib intersection points as possible. This was to match the analysis assumptions and to limit any local rib crippling. As

Table 1

Summary of the compressive strengths from the material tests on concrete cylinders.

\begin{tabular}{|c|c|c|c|c|c|c|c|c|}
\hline ID & $\mathrm{C} 1 \mathrm{~F}$ & $\mathrm{C} 2 \mathrm{~F}$ & $\mathrm{C} 3 \mathrm{~F}$ & $\mathrm{C} 4 \mathrm{~F}$ & $\mathrm{C} 5 \mathrm{~F}$ & $\mathrm{C} 6 \mathrm{~F}$ & $\mathrm{C} 7 \mathrm{~N}$ & $\mathrm{C} 8 \mathrm{~N}$ \\
\hline$f_{\mathrm{c}}$ & 146.0 & 146.1 & 135.7 & 136.0 & 145.3 & 142.3 & 141.2 & 122.0 \\
\hline
\end{tabular}

Table 2

Summary of the tests in bending (tensile strength tests).

\begin{tabular}{|c|c|c|c|c|c|c|c|c|}
\hline ID & B1F & $\mathrm{B} 2 \mathrm{~F}$ & B3F & B4F & B5F & $\mathrm{B} 6 \mathrm{~N}$ & B7N & B8N \\
\hline$f_{\mathrm{t}}$ & 14.0 & 14.3 & 12.4 & 8.8 & 8.0 & 6.3 & 5.1 & 5.2 \\
\hline
\end{tabular}




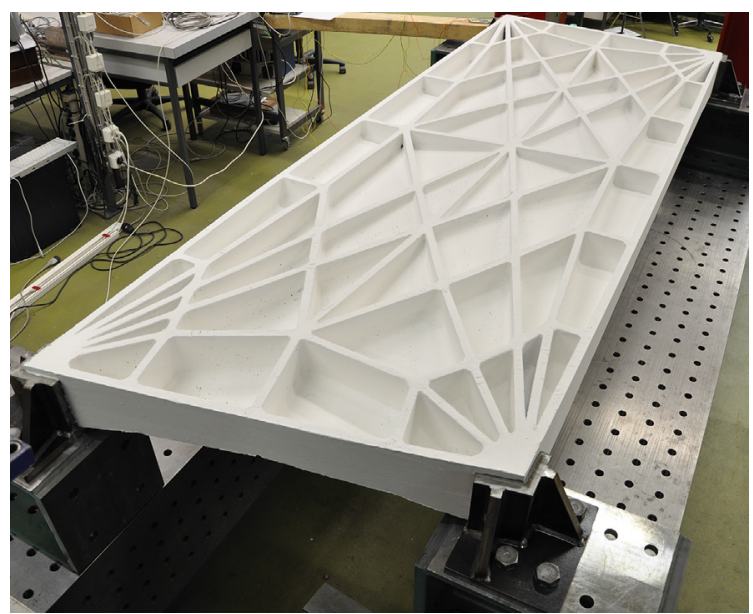

Fig. 12. Painted vaulted-floor connected to the testing frame with plated angle supports.

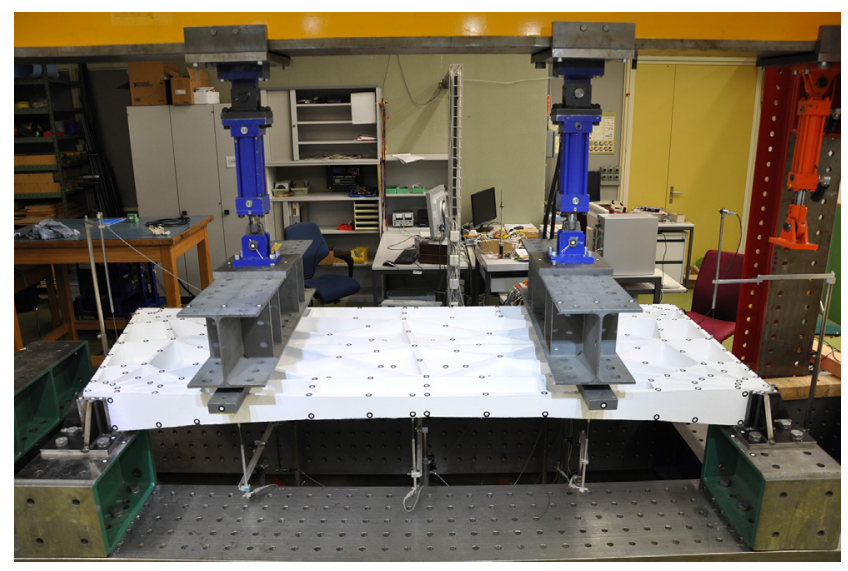

Fig. 13. Complete four-point-bending experimental setup for service loading.

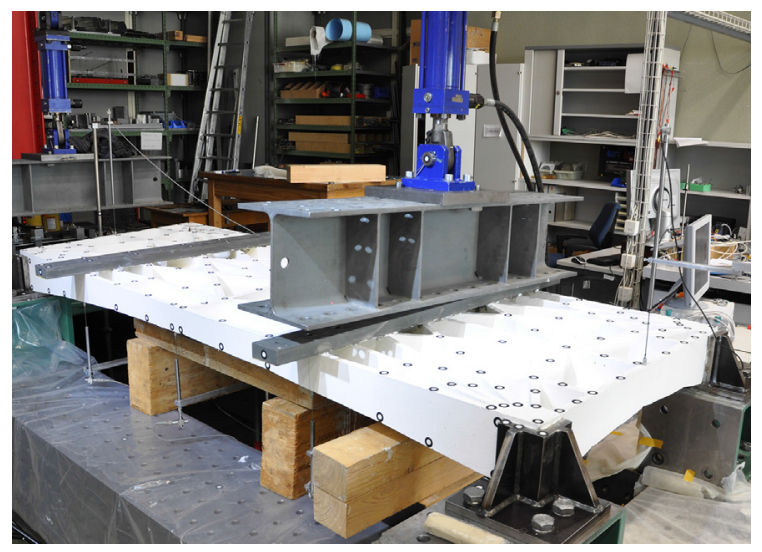

Fig. 14. Asymmetric loading setup for ultimate collapse load (left rectangular solid element was removed before testing).

the two longest sides of the floor were of different lengths, an average length of these two sides was taken to represent where the mid-span and quarter points should be located.

\subsection{GOM system}

The optical measuring system used in this research was the dynamic 3D motion analysis system by GOM (Fig. 15), which has

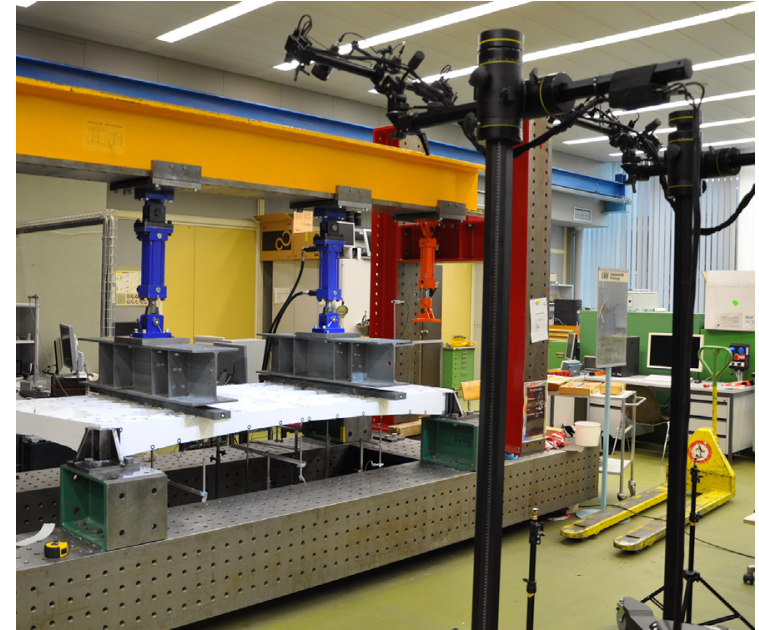

Fig. 15. The GOM setup consisted of two pairs of mounted cameras, and was used to measure the point cloud of black-white circular target stickers.

previously been used to measure displacements in 3D printed scale models of doubly-curved masonry groin vaults, subject to actuator-controlled support translations [19]. The hardware is an accurate tracking system for positioning components, using images captured with a stereo camera system to track reference point markers (black and white stickers) in 3D space via software PONTOS version 6.3.0-5. Each marker needs to be visible on both images so that each system can track the analysed object from a different viewpoint to triangulate its position.

Because the area of the floor's top face was greater than the maximum measuring area of a single system, two stereo camera systems were used for scanning the markers. The two systems were placed next to each other at a distance of $1.5 \mathrm{~m}$ from the floor and each camera configured and calibrated to scan an area of $1250 \mathrm{~mm} \times 1000 \mathrm{~mm}$. On each, the cameras were placed with a separation of $600 \mathrm{~mm}$ and at an angle of $20^{\circ}$. The accuracy of the measurements depends on the system calibration, where usually, the deviation of the sensor is between \pm 0.01 and \pm 0.05 pixels. This means that depending on the distance from the marker to the camera, the measurement accuracy will change. In the calibration process used for the test, the deviation of both systems was 0.025 pixels. The accuracy of the measurements varied from an average deviation of $0.015 \mathrm{~mm}$ in the row of markers closest to the sensors, to an average deviation of $0.037 \mathrm{~mm}$ at the furthest row. The point-cloud was transformed using reference points placed on the frame of the testing setup, to align the top surface of the floor with the global $x-y$ plane.

\subsection{Displacement transducers}

An array of eleven HBM induction, linear variable displacement transducers (LVDTs) were placed underneath the floor along the loading and mid-span lines (Fig. 16) as well as one LVDT at each side of the support ends from the topside. The LVDTs were fastened to the underside and topside of the floor with an epoxy putty, supported from cantilevering aluminium arms and connected to heavy steel stands, seen in Fig. 17. The verticality of the LVDTs was checked by spirit level and displacements were calibrated with a micrometer for the instrument scaling factors. Displacements were recorded to determine the performance of the floor under serviceability loading governed by deflection control, and for informative data with the ultimate loading test. For all instruments in the tests except the PONTOS system, data were recorded via two HBM Spider8 data loggers and through HBM CatmanEasy software. 


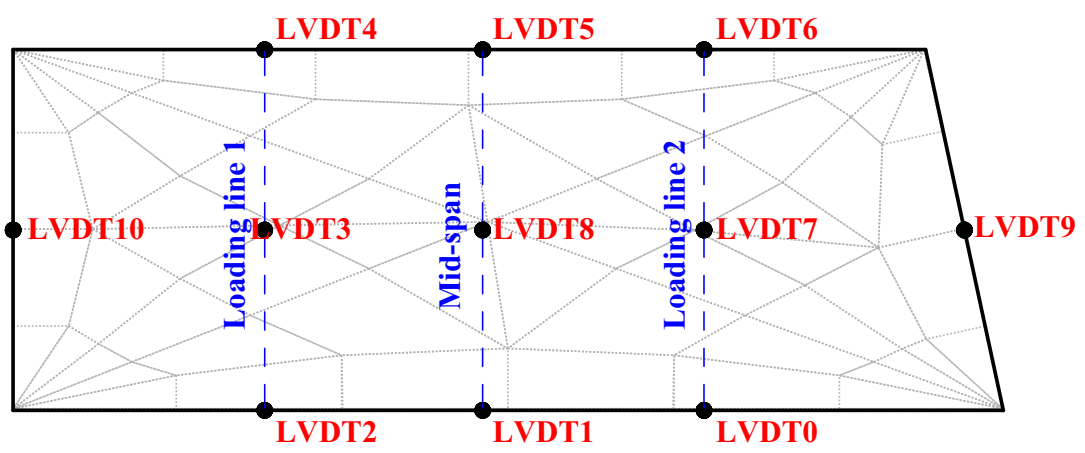

Fig. 16. Plan layout of the displacement transducers.

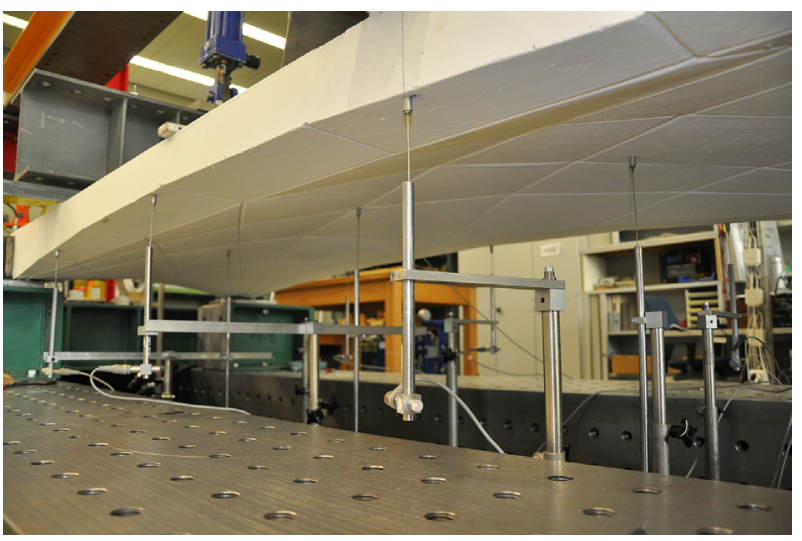

Fig. 17. An array of LVDTs on the underside of the floor measured vertical deflections.

\section{Results}

This section displays three sets of results: Section 5.1 gives the results of the cyclic and $24 \mathrm{hr}$ serviceability loading tests; Section 5.2 describes the ultimate loading test, with images and descriptions of the failure mode and the full load-displacement curve, and finally; Section 5.3 plots displacement contour plots of the data generated from the GOM PONTOS system for both loading cases.

\subsection{Serviceability loading}

The in-service loading that was used in the experiment, was from the ACI 437R-03 load test protocol [20]. This describes a cyclic load testing method that is characterised by staged loading levels across six cycles up to $100 \%$ of the intended maximum load, followed by a 24-hr sustained maximum load period after an intermediate rest of $30 \mathrm{~min}$. The initial six cycles consisted of two loading stages up to $50 \%$ load, followed by two loading stages up to $80 \%$, finishing with two loading stages up to $100 \%$ load. The complete loading profile can be seen in Fig. 18, with the horizontal dot- ted lines indicating load levels of $40 \%, 60 \%, 80 \%$ and $100 \%$, representing total loads of $4.72 \mathrm{kN}, 7.08 \mathrm{kN}, 9.44 \mathrm{kN}$ and $11.8 \mathrm{kN}$ respectively. The vertical red dotted lines at $6.3 \mathrm{hr}$ and $30.3 \mathrm{hr}$, show the start and finish times of the 24-hr test interval. During this 24-hr stage it was necessary to add a small additional load increment around hour 13, to stop the load level dropping below $100 \%$, due to some pressure loss in the hydraulic load system overnight.

Plotted in Fig. 19 are the displacement measurements taken from the LVDTs for the loading history. The LVDTs are grouped and plotted depending on their location: the three red lines are LVDT1, LVDT5 and LVDT8, which were the three instruments located at mid-span; LVDT0, LVDT2, LVDT3, LVDT4, LVDT6, LVDT7 are plotted with blue lines and represent the displacement transducers underneath the loading beams, and finally, LVDT9 and LVDT10, which were located at the support ends, are plotted in green. Throughout testing, displacements were always below $1.0 \mathrm{~mm}$, with a maximum value of $0.935 \mathrm{~mm}$ recorded at LVDT1, located at the longer span side; this was a little larger than the displacement at the floor's middle LVDT8. For comparison with a deflection limit of span/500, which would represent a strict design value for restricting damage to brittle finishes, the deflections are comfortably below $2580 / 500=5.16 \mathrm{~mm}$. The displacements were lower in magnitude below the loading points, with values around $0.5 \mathrm{~mm}$, and smaller at the support ends where they were below $0.1 \mathrm{~mm}$.

\subsection{Ultimate loading}

The asymmetric load case for ultimate loading was set-up with distributed line loading applied across the entire floor width at the right-hand-side quarter-span location. The total load plotted against the maximum vertical displacement from the displacement transducers is presented in Fig. 20. After an initial elastic region below about $10 \mathrm{kN}$ of applied force, the load-displacement curve becomes smooth and rounded up until $5 \mathrm{~mm}$ of vertical displacement. After this, continued cyclic pumping and unloading on the hydraulic jack, led to a further load increase up to the peak load of $42.6 \mathrm{kN}$. This peak load was reached at a maximum vertical dis-

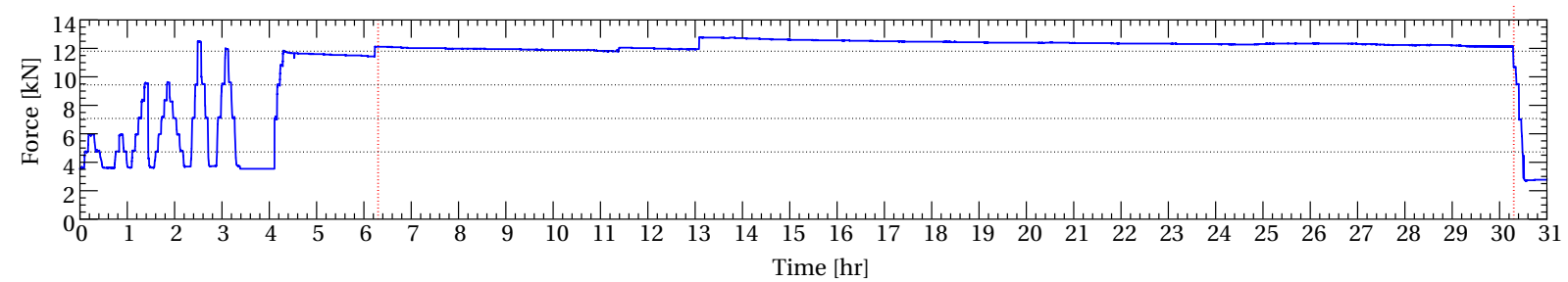

Fig. 18. Serviceability loading history according to [20] ACI 437R-03 load test protocol. 


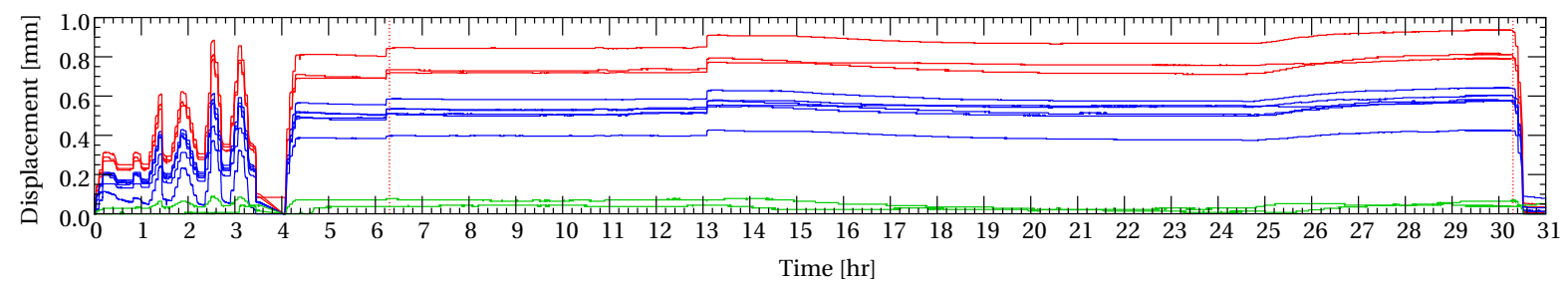

Fig. 19. Serviceability loading test displacement transducer measurements.

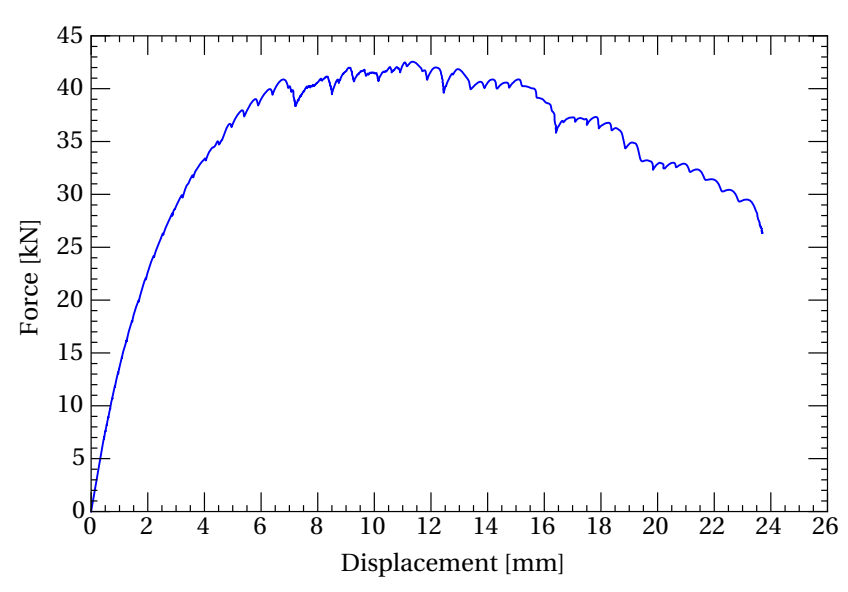

Fig. 20. Force-displacement curve for the ultimate load test.

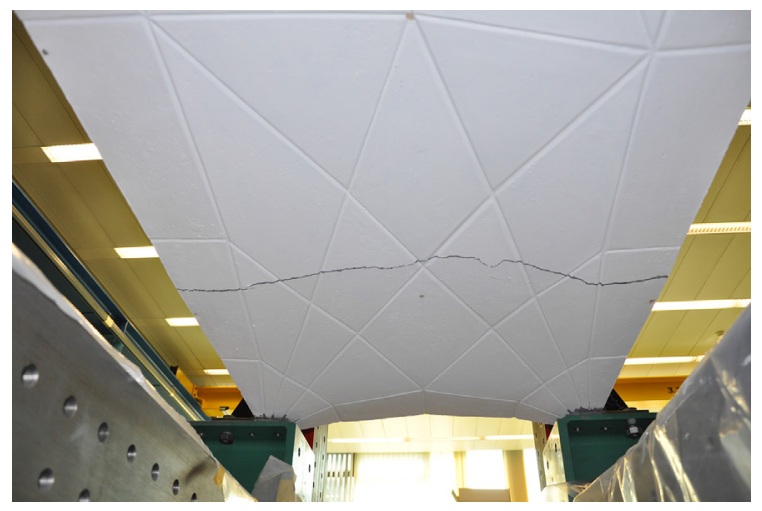

Fig. 21. Cross-width crack on the underside of the floor underneath the loading line.

placement of $11.3 \mathrm{~mm}$, and is just shy of four times the total load from the serviceability load test, and over 2.5 times the required factored load for ultimate limit state design. An unloading response after the peak load was observed, with repeated load cycles up until $24 \mathrm{~mm}$ of displacement, for which loading could not continue.

The prototype floor failed with a large cross-width crack forming underneath the loading beam. The crack initiation started at the edges of the floor sides at the lunettes, and then propagated inwards across the width meeting at the middle. This type of local failure initiation may have been caused by localised bending of the lunettes by the formation of $U$ shaped beams, with the ribs as the webs and the vault as the bottom flanges, spanning between the corner supports. The failure mechanism can be seen in Fig. 21, which shows the underside of the floor after the ultimate load test with all of the displacement transducers removed. It can also be seen from the top of the floor in Fig. 22, which shows the topside after the loading beam had been removed.

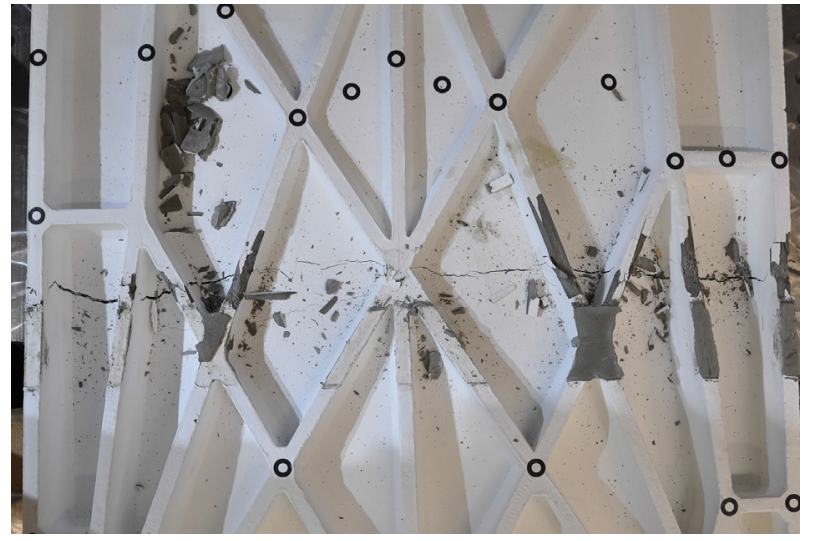

Fig. 22. Cross-width crack as seen from the top of the floor.

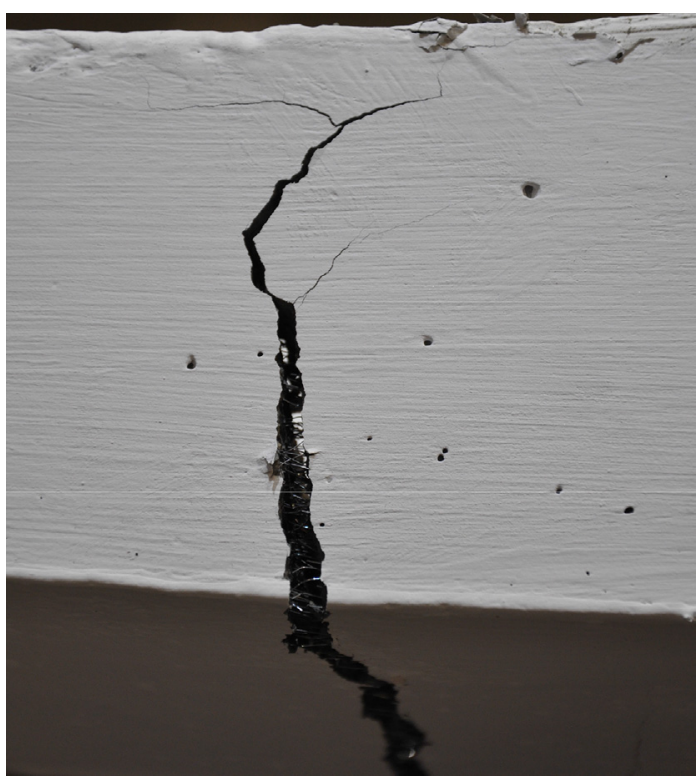

Fig. 23. Steel fibres prevented brittle failure.

No local buckling or web crippling of the $20 \mathrm{~mm}$ thick ribs was witnessed at either the loading points or along any other ribs. The use of steel fibres in the concrete mix led to a ductile ultimate failure mode and prevented any sudden brittle failure. This is evidenced in the load-displacement plot of Fig. 20, and it was clearly observable and audible during testing that the steel fibres were inhibiting the crack opening and propagation under the floor (Fig. 23). After the test, it was seen that there was generally a good distribution of fibres throughout the cross-section and floor volume, except for some localised regions where the fibres had settled slightly to the bottom vault during the concrete mixing and curing, 
although this is structurally advantageous to have more fibres in the bottom vault thickness.

\subsection{GOM data}

The GOM point-cloud data were used to generate the vertical displacement-field plots in Figs. 24-27, where the $z$-displacement in $\mathrm{mm}$ is relative to the $z$-coordinate from the start of the service and ultimate loading cases. The displacements in Fig. 24 are for time $t=26$ hours, which is near the end of the sustained $100 \%$ loading during the $24 \mathrm{hr}$ interval. The displacements match the behaviour seen with the LVDT measurements, with a mid-span hr cross-width region of highest displacements, with peak values of around $0.9 \mathrm{~mm}$ witnessed at the geometric centre of the floor and the longer span edge. The displacements are then $0.5 \mathrm{~mm}$ through the loading lines, before curtailing to zero at the supports. This plot shows a bias aligned with the longer span, causing more single-spanning arching action than vault action due to the aspect ratio of the floor.

Figs. 25-27 plot the displacement fields for loads of $37.5 \mathrm{kN}$, $42.6 \mathrm{kN}$ and $27.8 \mathrm{kN}$, corresponding to loading, peak load and unloading maximum displacements of $5.4 \mathrm{~mm}, 12.2 \mathrm{~mm}$ (close to $11.3 \mathrm{~mm}$ measured from LVDTs) and $49.5 \mathrm{~mm}$. The bias for the largest displacements around the asymmetric loading line on the right-hand-side can be seen clearly. A band of larger displacements can be seen in Fig. 25 with some higher deflections also seen towards the mid-span. This changes to a more concentrated maximum displacement on Figs. 26 and 27, where the floor was form-

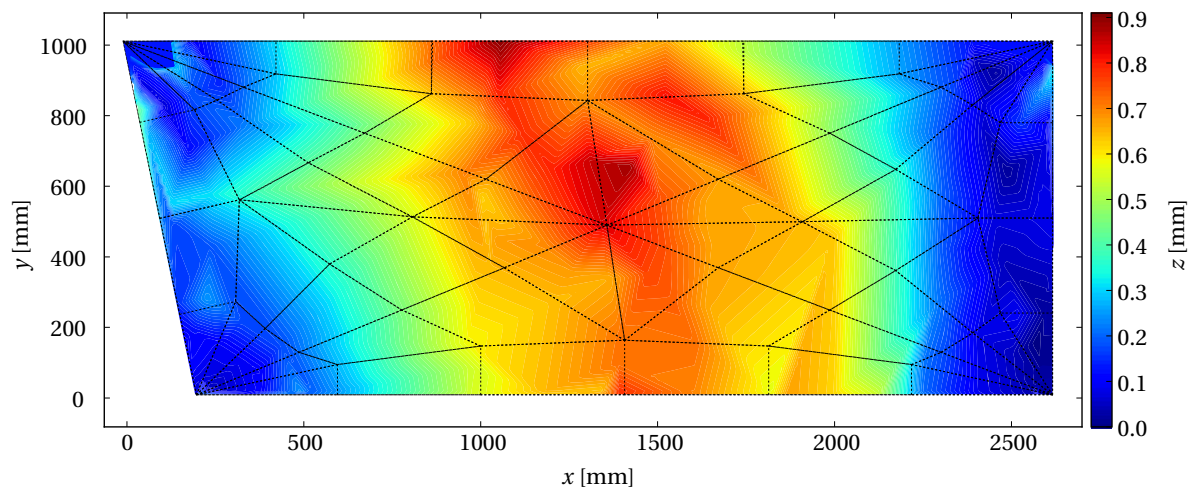

Fig. 24. Serviceability loading displacements (100\% load) from GOM data.

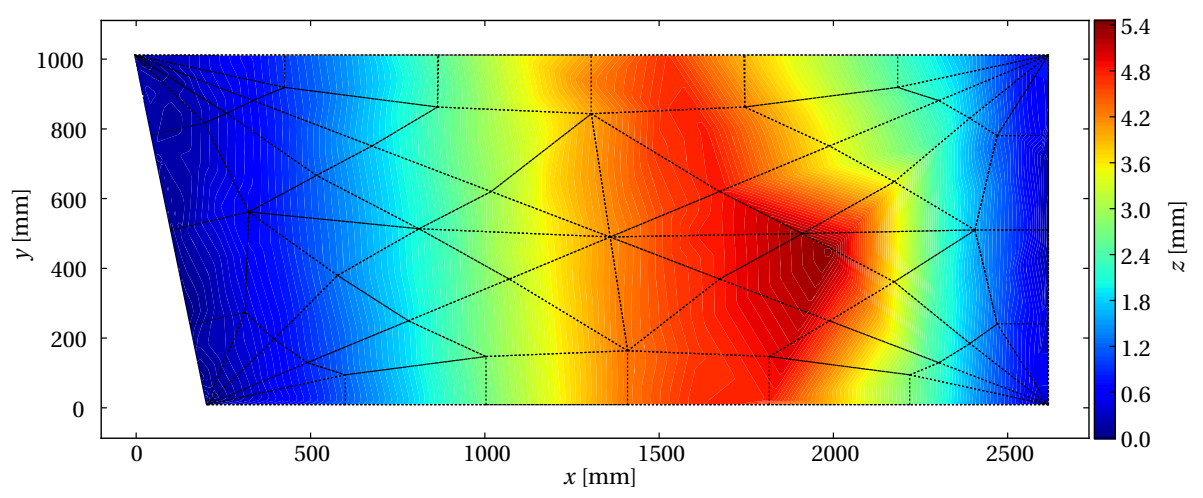

Fig. 25. Ultimate loading displacements ( $37.5 \mathrm{kN}$ load) from GOM data.

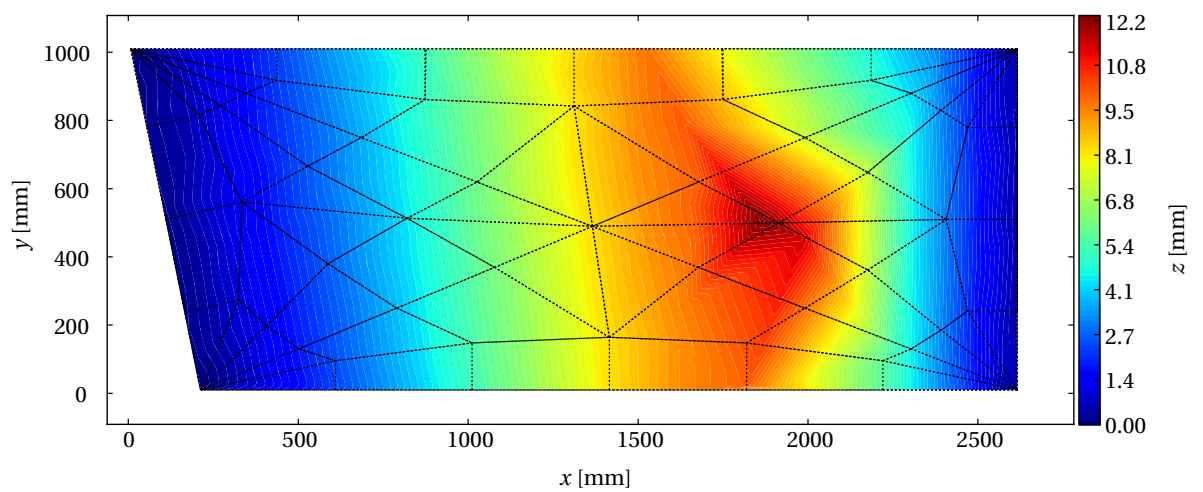

Fig. 26. Ultimate loading displacements ( $42.6 \mathrm{kN}$ peak load) from GOM data. 


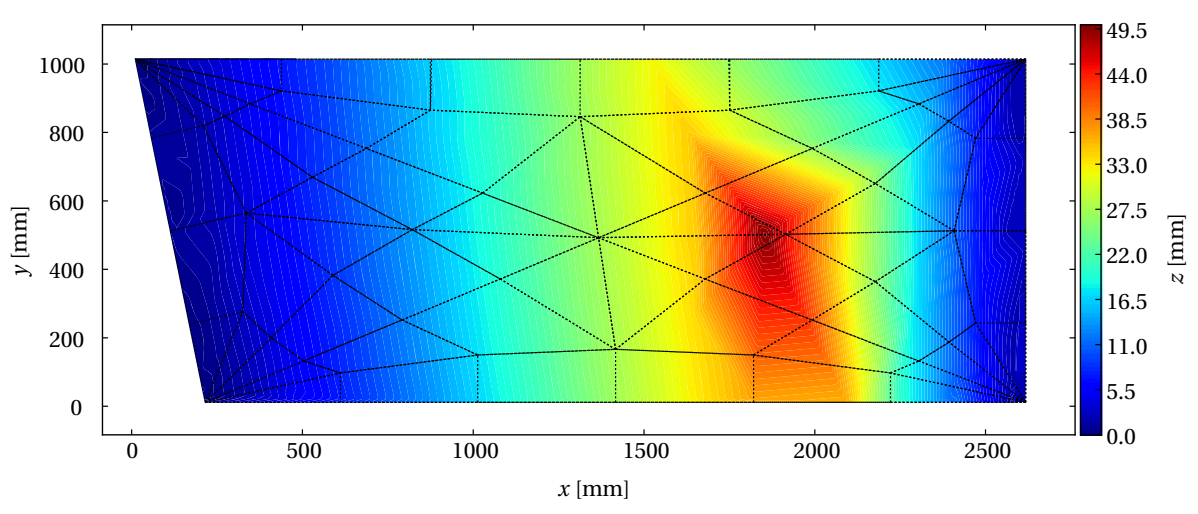

Fig. 27. Ultimate loading displacements ( $27.8 \mathrm{kN}$ unloading) from GOM data.

ing a hinge-like failure mechanism in both directions. This could be explained by the observed failure mechanism, whereby the crack formation across the width of the floor degraded the stiffness in main span direction, leading to load redistribution along the orthogonal direction and eventual folding to a central point under the applied load. For all cases, the maximum value occurs mid-way across the loading line, declining gradually towards the supports.

\section{Conclusions}

The presented thin-vaulted concrete floor, was the prototype element for a series of floors that will be installed at the NESTHiLo research and innovation unit, which is due to be completed in 2018. The floor offers a variety of benefits to pre-fabricated floor construction, as the units are light-weight, have functional internal voids, and the presented form finding and fabrication process can create custom project specific geometries. The geometry of the floor that was under experimental investigation has been described, the form finding methods and tools to generate this geometry have been explained, along with the digital fabrication procedure that was carried out. From the material tests, displacement measurements, and serviceability and ultimate loading tests, the following conclusions can be made.

The ultra-high-strength, fibre-reinforced, self-compacting concrete successfully filled the formwork without internal or external compaction, despite the relatively tight space created by the $20 \mathrm{~mm}$ vault and ribs. The steel fibres that were added to the mix, settled only slightly in some areas, and was of little negative consequence to the structural performance. The results of the concrete cylinder and rectangular beam tests gave a mean compressive strength value of $139.3 \mathrm{~N} / \mathrm{mm}^{2}$ and a mean tensile strength value of $11.5 \mathrm{~N} / \mathrm{mm}^{2}$ for the fibre-reinforced concrete (half this value when the mix was without fibres). These values are similar to those from which the mix was derived, although the choice of the concrete mix was not based on compressive strength.

An experimental test-rig was utilised, which had fixed steel supports at the corners bolted into a stiff steel test-rig frame to enable arching action by providing horizontal thrusts. A hydraulic loading system used single and double lines of spreader beams to load the floor for the serviceability and ultimate loading cases. An instrument combination of traditional displacement transducers and camera-system was used to record the displacements of the floor. The LVDTs were used at specific points and for calibration, while the camera system had the advantage of producing a full point cloud of data for all three spatial coordinates. However, the field of view of the cameras needed careful consideration, so as not to obstruct the target stickers with intermediate elements, which was particularly important during high deformations. The displacement readings for the cyclic and extended loading showed that the floor was stiff under service load, with deflections less than span/2500 (less than a millimetre), significantly lower than serviceability limits of span/500.

The floor possessed strength in excess of the design requirement, as after the ultimate loading test it was found that the floor carried 2.5 times the factored design load in a more critical asymmetric loading scenario. The asymmetric load case lead to a collapse load of $42.6 \mathrm{kN}$, for which the structural behaviour was ductile. This can be attributed in a large part to the use of steel fibres, which restrained the tensile cracking failure mode forming below the loading line. The failure mode consisted of a full-width crack on the underside of the floor within the vault thickness, which initiated at the sides of the floor at the lunette regions.

As a consequence of the research, various improvements have been made to the geometry and form finding pipeline of the floor system, giving incremental development changes to the floor unit in the larger floor geometries that will be seen in the NEST HiLo project. For example, further study is warranted in establishing the sensitivity of the floor to tie stiffness, as the fixed support conditions used in the presented test rig form an upper bound on support stiffness, as well as the location of such restraint for best capturing the horizontal thrusts.

\section{Acknowledgements}

The authors would like to thank Cristián Calvo Barentin for the set-up and provision of the GOM point-cloud data, Heinz Richner from the Institut für Baustoffe (IfB) at ETH Zurich for the material testing, Dominik Werne from the Institut für Baustatik und Konstruktion (IBK) at ETH Zurich for the testing of the prototype floor, Diederik Veenendaal and Masoud Akbarzadeh for the fabrication assistance with the floor and Patrik Meyer for helping with the steel supports and test-frame setup.

\section{References}

[1] NEST: next evolution in sustainable building technologies. HiLo: high performance Low energy. <http://hilo.arch.ethz.ch>; 2016.

[2] Veenendaal D, Bakker J, Block P. Structural design of the cable-net and fabric formed, ferrocement sandwich shell roof of nest HiLo. In: Proceedings of the international association for shell and spatial structures (IASS) symposium.

[3] Nagy Z, Svetozarevic B, Jayathissa P, Begle M, Hofer J, Lydon G, et al. The adaptive solar facade: from concept to prototypes. Front Archit Res 2016;5 (2):143-56.

[4] Lydon GP, Hofer J, Svetozarevic B, Nagy Z, Schlueter A. Coupling energy systems with lightweight structures for a net plus energy building. Appl Energy 2017;189:310-26.

[5] Ochsendorf J. Guastavino vaulting, the art of structural tile. New York: Princeton Architectural Press; 2010. 
[6] Davis L, Block P. Building SUDU: how to construct a sustainable urban dwelling unit, chapter Earthen masonry vaulting: Mexican and Catalan techniques. Berlin: Ruby Press; 2014.

[7] Block P, DeJong M, Davis L, Ochsendorf J. Tile vaulted systems for low-cost construction in Africa. J Afr Technol Dev Forum (ATDF) 2010(7-1):4-13.

[8] Guastavino/Collins Collection. Drawings and archives. Avery Library, Columbia University.

[9] Block P, Ochsendorf J. Thrust network analysis: a new methodology for three dimensional equilibrium. I Int Assoc Shell Spatial Struct 2007(48-3):167-73.

[10] Block P. Thrust network analysis: exploring three-dimensional equilibrium PhD dissertation. Cambridge (USA): Massachusetts Institute of Technology; 2009.

[11] Adriaenssens S, Block P, Veenendaal D, Williams C. Shell structures for architecture. Form finding and optimization. London: Routledge; 2014.

[12] BLOCK Research Group. ETH Zurich. RhinoVAULT - Designing funicular form with Rhino. <http://block.arch.ethz.ch/brg/tools/rhinovault>; 2014.

[13] Rippmann M, Lachauer L, Block P. Interactive vault design. Int J Space Struct 2012;27(4):219-38
[14] Swiss building codes SIA Zurich. SIA 261: actions on structures. Schweizer Norm - Swiss Society of Engineers and Architects; 2003.

[15] SAP2000. Walnut Creek (California): Computers and Structures Inc (CSI); 2014.

[16] Rippmann M, Block P. Digital stereotomy: voussoir geometry for freeform masonry-like vaults informed by structural and fabrication constraints. In: Proceedings of the IABSE-IASS symposium, London, UK.

[17] Grünewald S, Shionaga R, Walraven J. Self-compacting fibre reinforced concrete applied in thin plates. Rheol Process Constr Mater 2013:341-8.

[18] López López D, Veenendaal D, Akbarzadeh M, Block P. Prototype of an ultrathin concrete vaulted floor system. In: Proceedings of the IASS-SLTE 2014 symposium.

[19] Van Mele T, McInerney J, DeJong M, Block P. Physical and computational discrete modeling of masonry vault collapse. In: Proceedings of the 8th international conference on structural analysis of historical constructions, Wroclaw, Poland.

[20] ACI Committee 437. 437R-03: strength evaluation of existing concrete buildings. Committee report; 2003. p. 1-28. 